\title{
Effects of oil shocks on EMU exports: technological level differences
}

\section{Martin Hodula, ${ }^{1}$ Bohdan Vahalík ${ }^{2}$}

\begin{abstract}
This article provides some new empirical perspectives on the relationship between oil-market fluctuations and technological structure of EMU export. We rely on a time-varying parameter VAR model to capture the reaction of different technological structures of EMU export to various oil-market innovations in the period 2002-2015. Our results can be summarized as follows: (1) increase in crude oil production is likely to reduce oil prices and therefore increases all EMU exports due to lower production and transportation costs; (2) increase in global demand is more likely to be transmitted to goods with higher added value; (3) high-tech exports decrease in the first months after the global demand shock as a result of a delayed investment decision process; (4) increasing oil prices yield only marginal effect on EMU export.
\end{abstract}

Key words: EMU, export, technological structure, TVP-VAR

JEL Classification: C32, F14, O52, Q41, Q43

Received: 14 March 2017 / Accepted: 18 October 2017 / Sent for Publication: 8 December 2017

\section{Introduction}

The beginning of a new millennium was marked by a high fluctuation of oil prices. Even though the share of oil on trade and production has decreased during the last few decades, it still represents an important input for the production of goods, energy and international transport. Oil, as one of the primary sources of industrialized countries' performance, is therefore still in the spotlight of economic research.

From the macroeconomic standpoint, oil prices affect inflation and economic growth as well as production costs. Despite the fact that oil demand and supply react sluggishly to oil price changes, it significantly influences the economic performance of both oilexporting and oil-importing countries. Therefore, oil-price fluctuations represent a very important indicator influencing economic life in oil-dependent countries and serve as a

\footnotetext{
${ }^{1}$ VŠB-Technical University of Ostrava, Economic Faculty, Department of Economics, Sokolská třída 33, 701 21 Ostrava, Czech Republic, e-mail: martinhodula@gmail.com

${ }^{2}$ VŠB-Technical University of Ostrava, Economic Faculty, Department of European Integration, Sokolská třída 33, 70121 Ostrava, Czech Republic, e-mail: bohdanvahalik@gmail.cz
}

(C) 2017 by the authors; licensee Review of Economic Perspectives / Národohospodářský obzor, Masaryk University, Faculty of Economics and Administration, Brno, Czech Republic. This article is an open access article distributed under the terms and conditions of the Creative Commons Attribution 3.0 license, Attribution - Non Commercial - No Derivatives. 
predictor of possible economic development due to its high influence on economic agents' expectations.

The aim of this paper is to study the effects of oil-shocks on technological structure of European Monetary Union (EMU) export across the period 2002-2015. Only a modest amount of literature deals with the impact of oil-shocks on export of oil-importing economies. EMU offers a very specific sample of developed countries which may be characterized by many common attributes. First, all EMU countries are net importers of oil (in 2015, the group produced only $2.8 \%$ of its own crude oil consumption). Second, due to generally high consumption, EMU is one of the most important trading partners for oil-exporting countries. Third, all countries of the EMU share a common commercial policy and a single currency. Hence, the European commercial law affects extra-EU trade relations of all EMU countries equally and, due to a single currency, none of the EMU countries is able to alter its external economic relations by influencing domestic currency. Finally, EMU countries are the biggest exporter in the world. In 2016, its share on total world export reached $26 \%$. Foreign demand is thus an important source of EMU economic activity, income and employment.

Our results are closely linked to papers of Kilian et al. (2009) and Riggi and Venditti (2015) who also examine the oil market and its relations to real economic activity or the level of export. We contribute to the existing literature by investigating the effects of oil-price shocks on technological structure of export of oil-importing countries. An average share of low-, medium- and high-tech products on extra-EMU exports were $17 \%, 53 \%$ and $31 \%$ in the observed period. We believe that a different production process across the technological levels accounts for a different amount of imported oil or oil products which may have a diverse effect on the export of goods according to the level of technological development. Therefore, we believe that our study offers a very original view on international trade.

We use a time-varying parameter VAR model (TVP-VAR) with stochastic volatility and heteroscedasticity in the innovations. Specifically, we expect different reaction of EMU export by its technological level as well as different reaction in various periods of economic cycle. Thus, we suppose that our paper is to enrich contemporary literature on technological structure of export and show differences of reaction of each group of goods to a given shock. The final amount of EMU export depends on external demand. However, according to economic theory, it is not clear whether the rise in oil-prices, which is still a significant input element of production and transportation, would cause a reduction or increase of export from the EMU countries. Moreover, we may assume that changes in oil-prices affect each technological group of exports differently depending on the share of oil as input to their production.

There are many direct and indirect effects through which changes in oil prices may affect the level of country's export (Figure 1). First, we consider the exchange rate effect. Oil price upswings negatively influence terms of trade of oil-dependent countries. For example, floating EUR/USD exchange rate may depreciate to restore economic 
balance resulting in higher export under the weakening of the euro. As we have already mentioned, oil is an important production input and therefore as such, its higher price negatively affects output, domestic demand and unemployment through the rise of the production costs. If the main partners of oil-importing countries are also oil-importers ${ }^{3}$, low demand on goods, triggered by higher oil prices, negatively affects EMU export. However, if the main trade partners are oil-exporting countries (receiving high revenues arising from higher oil-prices), an increase in oil prices may increase the demand for imported goods from oil-importing country.

Figure 1 Theoretical effect of oil price on macroeconomic variables

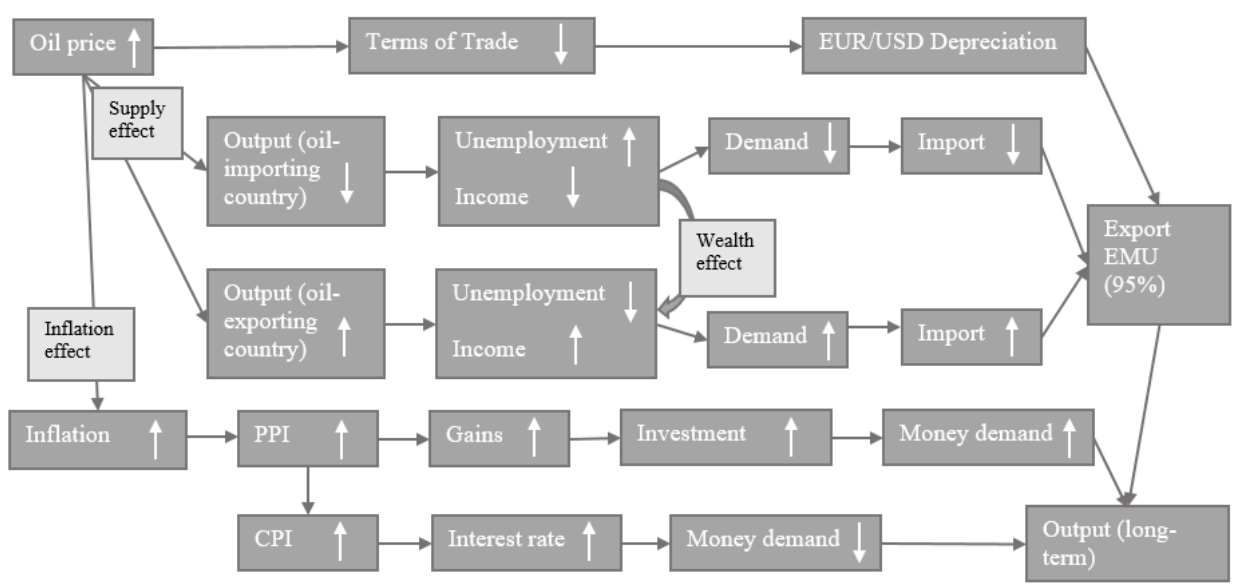

Source: authors

The resulting effect of an increase in oil prices on export will therefore be determined by the fact if the change of demand on goods will be lower than the change of oil prices. Second, higher oil prices also boost inflation and affect demand for money. The consumer limited by budget constraints has to compensate higher oil prices by lowering consumption of other goods. Lower savings will then be corrected by higher interest rates tightening economic activity. Moreover, uncertainty about the oil-price development triggered by oil-price shock may negatively influence investment decisions depending on expectations.

The rest of the paper is organised as follows: section 2 provides literature review of oilmarket studies matching our focus. Section 3 describes our estimation of different technological export structures. Section 4 lays down details on used time-varying VAR model. Section 5 contains introduction of data and results of misspecification tests. Section 6 presents results of impulse response analysis of oil-market related shocks and their effects on EMU export divided by technological level of manufacturing in different periods and section 7 concludes.

\footnotetext{
${ }^{3}$ According to UNCTAD (2017), 95\% of the EMU total export goes to the oil-importing countries.
} 


\section{Literature review}

Historical development of oil markets has shown that oil-price volatility has a huge impact on the world economy. Studies of oil-price effect on macroeconomic environment were started by Hamilton (1983). He studies the relationship between oil prices and real economic activity and reports a high statistically significant correlation between recessions and oil shocks for the period 1948-1972. Hamilton (2012) adds that global oil-price shocks during the second half of the 20th century were usually closely related to the Middle East conflicts. However, a decrease in global oil supply in 2005 and 2007 and increasing demand for oil and price bubbles were the main factors of oilprice shocks in 2007-2008.

Most of the economic studies, however, confirm a declining effect of oil-price shocks on economic activity during the last decades with the break-time started in the 80s (Edelstein and Kilian, 2009; Blanchard and Gali, 2009). These results are confirmed by Baumeister and Peersman (2013) who find lower influence of oil-supply shocks on US economy and substantial decline in the short-run price elasticity of oil-demand since the mid-80s. Blanchard and Riggi (2013) claim that this change was caused by more efficient use of oil, lower real wage rigidity and better monetary policy. ${ }^{4}$ Current literature widely accepts that oil-price is determined predominantly by demand conditions (Hamilton, 2009). For example, Korhonen and Ledyaeva (2010) investigate the relation between economic growth through international trade channels. They assume that (1) higher oil prices cause a negative supply shock that slowdowns growth in oil-importing countries and, at the same time, (2) higher economic growth in oil-exporting countries may lead to higher demand from oil-importers. Papers of Hamilton (2009), Cologni and Manera (2008) or Lardic and Mignon (2008) prove that the increase in oil prices strongly affects economic activity of most countries and increases prices in the period before 2008. Additionally, Kilian (2010) finds that the impact of oil-price shocks (expenditure shock for oil-importing countries) on economic activity may be mitigated by the quantity of domestically produced oil. Unfortunately, this is not the case of the EMU countries as they do not have any significant oil reserves.

Methodologically, most of the empirical literature focused on the subject employ vector autoregression (VAR) models. Cunado et al. (2015) employ structural VAR model to determine the effect of oil shocks on Asian countries. They find that oil-demand shocks influence economic activity in given countries while oil-supply shocks do not have a significant impact. Using structural VAR model, authors as Bernanke et al. (1997), Lee and Ni (2002), Peersman (2005) or Peersman and Van Robays (2009) identified oilsupply shocks, oil-demand shocks and oil-specific demand shocks. Kilian and Hicks (2012) or Aastveit et al. (2015) found that surge of real oil-price in the 2000s was caused by a rapid growth of demand in emerging economies.

Closer to our topic, several studies investigate the effect of oil-market shocks on current account. Backus and Crucini (2000) and Baffes (2007) study several channels transmit-

\footnotetext{
${ }^{4}$ There are many other research papers analysing the effect of oil price shocks and real economic activity (see Brown and Yucel, 2002; Kilian, 2008; Hamilton, 2008; Elder and Serletis, 2010 or Jo, 2014).
} 
ting the impact of oil shocks to trade balance. In the case of trade channel, oil-price impact is mainly dependent on quantity and price of both imports and exports. They also find that effectiveness of transmission of trade channel depends on the level of economic development, state of the economy and its role as an oil-exporting or oilimporting country. Backus and Crucini (2000) or Schubert (2009) agree that oil-price shocks can impact negatively trade balance of oil-importing countries because imported oil directly enters into the input for domestic production. ${ }^{5}$

Riggi and Venditti (2015) analysed time-varying effect of oil-price shocks on EMU export. They find that EMU exports have become less dependent on oil-supply shortfalls but otherwise more dependent on foreign productivity shocks since 1980s. Rubin (2009) finds that increasing prices of oil make transport costs excessively higher, thus negatively affecting trade prices and representing a big obstacle to international trade. Rasmussen and Roitman (2011) conclude on the sample of small economies that the impact of higher oil-price on oil-importing economies is generally small due to export revenues growth.

We are following the results of Kilian et al. (2009) who examine the effect of oil supply and demand shocks on current account of oil-exporting and oil-importing countries during the period 1975-2006. They find that oil-supply shocks have a relatively small and short-lived impact on oil trade balance, but oil-demand shocks create large and persistent oil trade deficits in oil importing countries. We also follow paper of Gossé and Guillaumin (2011) who analyse the impact of monetary, financial and oil-price shocks on EMU since 2000 using structural VAR model. They find a high diversity of reactions inside the EMU but the repercussions of the oil shocks were fairly similar in all EMU countries, except Netherlands.

\section{On the estimation of EMU export technological levels}

International databases of foreign trade do not provide enough information about technological level of export for each country. Lall (2000) uses disaggregated data by Standard International Trade Classification (SITC) at the 3-digit level from UNCTAD database, revision 2. We upgraded the classification of technological level of exports of disaggregation by SITC, revision 3. The reason for this step is the current form of the UNCTAD database providing new SITC rev. 3 data which begins in the year 2002 . However, the difference between SITC classification rev. 2 and rev. 3 at the 3-digit level is not very significant, mostly renaming or renumbering individual items. Big changes occurred only at the lower technological levels. ${ }^{6}$

\footnotetext{
${ }^{5}$ For case studies see Le and Chang (2013) or Bao (2014).

6 It should be noted that the sole division of export by technological classification fails to capture the technological complexity within the same product category. For example, it cannot provide information about quality differences within telecommunication equipment and pars (764) which contain modern smartphones as well as regular plastic home cells or specially designed shoes versus mass-produced shoes within category footwear (851).
} 
The aggregation at the 3-digit level brings satisfactory results because it provides a proxy for capturing considerable technological differentiation among traded goods. ${ }^{7}$ To better understand the meaning of each export group by technological level, we provide short descriptions:

- low technology export (LT) has generally low skill requirements for production. Within each group, it contains usually non-differentiated products which compete via price. The final price is significantly dependent on the cost of labour in the country. In the past, production of this type of product recorded massive shifts in the world economy from rich to poor countries. Another key feature of low-tech product is, in general, its low income elasticity as demand grows very slowly in relation to growing income. Typical are also low barriers to entry and economies of scale. Low-tech exports include manufactures of textile, garment and footwear, non-metallic mineral manufactures, iron and steel and manufactures of metal.

- medium technology export (MT) covers scale-intensive technologies in capital goods and intermediate products as well as a great deal of knowledge and skills. Production requires advanced and complex technologies and skills and moderately high level of research and innovation. This type of products creates the main part of modern market economies' industry and generates important linkages with other types of industries in horizontal as well as vertical production network. International division of labour is lower and companies tend to create new production capacities in the place of demanded market because transport costs may be higher. Barriers to entry are higher than in the low-tech goods markets and require supply networks. The production is usually massive with higher capital requirements. Medium-tech exports contain products of automotive industry, process industries including chemicals and processed metals, and engineering products.

- $\quad$ high technology export (HT) is characterized by a high share of added value which is based on high investments in research and innovation. Production is based on advanced and fast-changing technologies which require a high level of specialized technical skills, ideas and design. Production is often based on cooperation among companies, universities and research organizations. Producers are usually big multinational corporations or highly specialized companies. Countries exporting such products achieve a high degree of skills, technology and supplier network. High technology products contain electric and electronic manufactures as well as pharmaceuticals, aircraft equipment, measuring devices, optical products, etc.

Figure 2 shows the technological structure of EMU export. From a simple visual inspection of the data in levels, we can see that they generally co-move with no visible outliers. The correlations between particular groups are indeed high ( 0.96 on average).

\footnotetext{
${ }^{7}$ This paper does not deal with the whole technological classification, but includes only exports based on technological basis of comparative advantages, thus it excludes primary products and resource based manufactures.
} 
Figure 2 Technological levels of EMU export

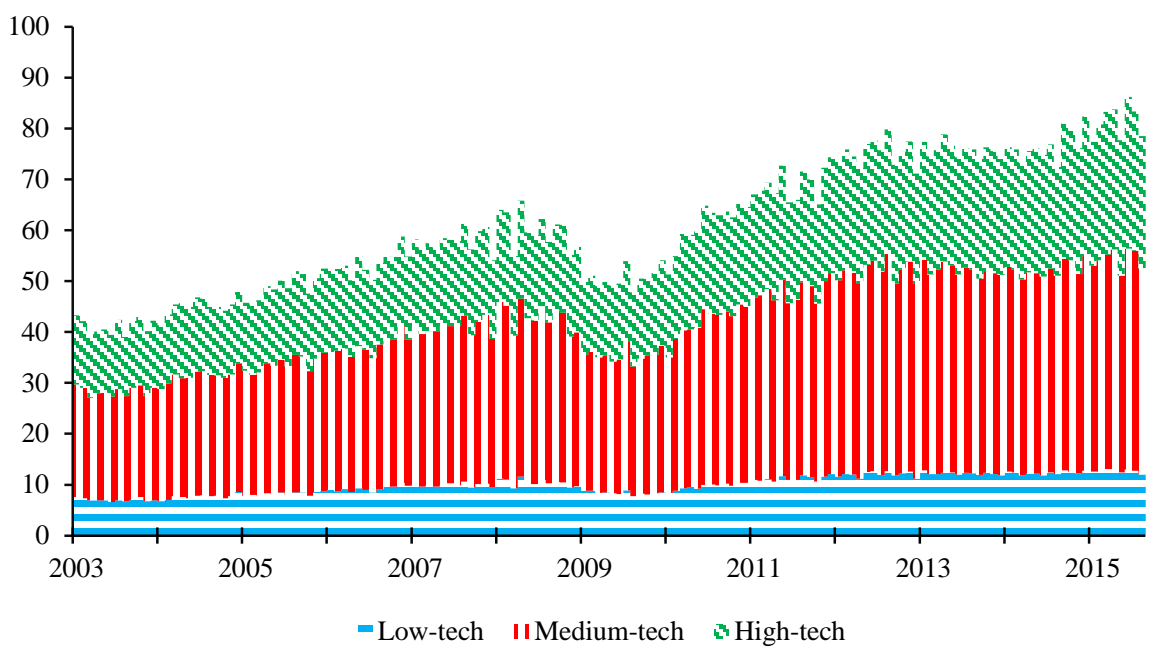

Source: EUROSTAT, authors' computations

\section{Methodology}

The apparent instabilities in the oil-market developments and export of goods suggest that modelling the transmission of oil-related shocks adequately requires an empirical framework that can account for changes over time as well as to capture possible nonlinearities. In addition, time-varying structure will also allow incorporating an adaptive behaviour of economic agents as a result of an on-going learning process.

To study the effect of the innovations in oil-market on technological structure of EMU exports, we use a time-varying parameter VAR model (TVP-VAR) with stochastic volatility and heteroscedasticity in the innovations as in Primiceri (2005). The TVPVAR not only allows the sizes of the shocks to change over time but also allows the VAR coefficients to be time varying. The time variation in the VAR coefficients can help us to capture the potential structural changes caused by changes on the oil markets.

We jointly model four variables. Our model consists of crude oil production $q_{t}^{\text {oil }}$, seasonally adjusted export $e x_{t}$ grouped according to different technological levels (low-, medium- and high-tech), global real economic activity index rea $a_{t}$ and real price of oil $p_{t}^{\text {oil }}$. Note that the different technological levels of export enter the model one-by-one (we therefore estimate three different models). We consider the following notation:

$y_{t}=a_{t}+B_{1, t} y_{t-1}+\ldots+B_{p, t} y_{t-p}+\varepsilon_{t}$, where $t=s+1, \ldots, n$ 
where $y_{t}$ is the vector of endogenous variables which consists of $y_{t}=\left\lfloor\Delta q_{t}^{\text {oil }}, \Delta e x_{t}, \Delta r e a_{t}, \Delta p_{t}^{\text {oil }}\right\rfloor$ with $\Delta$ being the difference operator; intercept $a_{t}$ and parameters $B_{t}$ are all time varying. The $\varepsilon_{t}$ denotes heteroscedastic unobservable shocks with zero mean and time-varying covariance matrix of the residuals $\Omega_{t}$. The stochastic covariance matrix of model residuals is factored as $\operatorname{VAR}\left(\varepsilon_{t}\right) \equiv \Omega_{t}=A_{t}^{-1} \Sigma_{t} \Sigma_{t}^{\prime}\left(A_{t}^{-1}\right)^{\prime}$, where $A_{t}$ is a lower-triangular matrix that models the contemporaneous interactions among the endogenous variables and $\Sigma_{t}$ is a diagonal matrix that contains the stochastic volatilities, defined as:

$$
A_{t}=\left(\begin{array}{cccc}
1 & 0 & 0 & 0 \\
a_{21, t} & 1 & 0 & 0 \\
a_{31, t} & a_{32, t} & 1 & 0 \\
a_{41, t} & a_{42, t} & a_{43, t} & 1
\end{array}\right) \quad \Sigma_{t}=\left(\begin{array}{cccc}
\sigma_{1, t} & 0 & 0 & 0 \\
0 & \sigma_{2, t} & 0 & 0 \\
0 & 0 & \sigma_{3, t} & 0 \\
0 & 0 & 0 & \sigma_{4, t}
\end{array}\right),
$$

The TVP-VAR model can then be summarized as follows:

$y_{t}=X_{t}^{\prime} B_{t}+A_{t}^{-1} \Sigma_{t} u_{t}$, where $X_{t}=I \otimes\left[1, y_{t-1}^{\prime}, \ldots, y_{t-1}^{\prime}\right]$ and $\operatorname{VAR}\left(u_{t}\right)=I_{n}$,

Allowing for time variation in both the coefficients and the variance-covariance matrix leaves it up to the data to determine whether the time variation of the linear structure comes from changes in the size of the shock and its contemporaneous impact or from changes in the propagation mechanism. The three drifting processes of the modeled system follow a random walk process and take following state equations:

$B_{t}=B_{t-1}+\eta_{t}$,

$\alpha_{t}=\alpha_{t-1}+\mu_{t}$,

$\log \sigma_{t}=\log \sigma_{t-1}+\zeta_{t}$,

where $\alpha_{t}$ is the vector of non-zero and non-one elements of the matrix $A_{t}, \sigma_{t}$ is the vector of the diagonal elements of the matrix $\Sigma_{t}$ and $B_{t}$ is the matrix of stacked timevarying coefficients from (1). The vector of innovations $\left[u_{t}^{\prime}, \eta_{t}^{\prime}, \mu_{t}^{\prime}, \xi_{t}^{\prime}\right]$ is distributed according to the following assumption:

$$
\left[\begin{array}{c}
u_{t} \\
\eta_{t} \\
\mu_{t} \\
\xi_{t}
\end{array}\right] \sim \mathrm{N}(0, \mathrm{~V}) \text {, with } \mathrm{V}=\left[\begin{array}{cccc}
\mathrm{I}_{\mathrm{n}} & 0 & 0 & 0 \\
0 & Q & 0 & 0 \\
0 & 0 & S & 0 \\
0 & 0 & 0 & W
\end{array}\right]
$$

where $Q, S, W$ are positive definite matrices and $\eta_{t}, \mu_{t}, \zeta_{t}$ are independent over $t$ and $u_{t}$. 
The estimation procedure in TVP-VAR can be constructed using the Markov chain Monte Carlo (MCMC) methods (details on the procedure are available in the Appendix of Primiceri, 2005). Since the TVP-VAR has a larger number of parameters than the conventional VAR and our sample size is small, we estimate the model using the Bayesian method. We use uninformative priors for estimation and follow Primiceri (2005), Koop et al. (2009) and Korobilis (2013) to use a training sample (the first 40 observations) to calibrate the key prior hyperparameters. The posterior distribution is simulated using Gibbs sampling. The results presented in this paper are obtained using the following hyperparameter values: $k_{Q}=0.05, k_{S}=0.01$ and $k_{W}=0.0001$, similarly to Kang et al. (2015). For details on prior selection process, please consult the Appendix 1.A.

Once the reduced-form VAR is consistently estimated, the resulting estimates are then used to construct the structural VAR representation through the relationship $u_{t}=A_{t}^{-1} \Sigma_{t} \varepsilon_{t}$, in the following:

$$
y_{t}=X_{t}^{\prime} B_{t}+\Xi_{t} u_{t},
$$

that differs from (3) because the $n \times n$ matrices $\Xi_{t}$ are not necessarily lower triangular. To be able to compute our SVAR, we must assume that for any $t, \Xi_{t}$ contains at least $\frac{n(n-1)}{2}$ restrictions that guarantees identification. Note that for every draw of $\Omega_{t}$, we solve the system of equations given by $\Xi_{t} \Xi_{t}^{\prime}=\Omega_{t}$.

\section{Identification scheme}

The literature on oil-market shocks has provided evidence that oil prices are not only determined by supply-side factors but they are also driven by demand (see Barsky and Kilian, 2002; Kilian, 2008; Hamilton, 2009). Kilian (2009) shows the differences between oil supply and demand shocks by imposing contemporaneous exclusion restrictions in a monthly VAR model and includes world oil production and the real price of crude oil. An oil supply shock is the sole disturbance that has any immediate effect on the level of oil production. Moreover, global oil production does not respond immediately to oil demand shocks drawn from world production. This would suggest that the short-run oil supply curve is close to vertical position.

In general, we can identify three types of oil-market shocks: (i) changes in the world oil production which result from geopolitical and social events (war, civil unrest, OPEC policy decisions), (ii) changes in the global economic activity that affect the demand for oil and other commodities, and (iii) changes in agents' expectations about crude oil production relative to demand (for details see Alquist and Kilian, 2010 or Kilian and Murphy, 2014). Derived from previous work of Baumeister and Peersman (2013) and Buetzer et al. (2012) who use sign restrictions, we can summarize some key findings on the relationship between oil markets and real economy. First, after a negative oil production shock, world production decreases in respond while the price of oil is increasing. Second, after positive oil demand shock introduction drawn from unexpected world production increase, world oil production is not affected while the oil-price increases. Third, oil market specific shocks do not affect world oil supply on impact, they decrease the global economic activity and raise the price of oil. 
Based on these facts, we present here a slightly modified model of the global market for crude oil which is focused on deriving the effects of oil market shocks on technological structure of EMU. Vast literature suggests that the variance-covariance matrix of the reduced-form residuals is a Cholesky identification scheme, restricting the contemporaneous relationship matrix to be lower triangular:

$$
\Xi_{t}=\left(\begin{array}{cccc}
x & 0 & 0 & 0 \\
x & x & 0 & 0 \\
x & x & x & 0 \\
x & x & x & x
\end{array}\right) \cdot\left(\begin{array}{c}
u_{t}^{\text {prod }} \\
u_{t}^{\exp } \\
u_{t}^{\text {rea }} \\
u_{t}^{\text {price }}
\end{array}\right),
$$

The rationale for this SVAR setting is as follows: first, as found by previous contributions listed above, the oil production is not responding at impact to oil-price increase, suggesting some form of fixed costs holding the production on the same level; second, we set the EMU export (on various technological levels) to respond immediately on any production shortage and to respond with a lag to changes in price of oil and real global economic activity as we can expect long-term export contracts; third, real global economic activity responds immediately to changes in oil production and export and fourth, price of oil is responding to both supply and demand shocks at impact.

The imposed restrictions allow us to specify some specific oil market innovations as in Kilian (2009): (a) crude oil supply shocks (oil supply shocks for short) are defined as unexpected increase in crude oil production; (b) aggregate demand shocks which are drawn from real global economic activity index and (c) oil-specific demand shocks (oil demand shocks for short) taken from innovation in real price of oil.

The lag length in our benchmark model is set to $p=7$ which seems enough to allow for sufficient dynamics in the system and to capture lags in the transmission of oil shocks. We have experimented with different lag number which yields comparatively identical results. However, due to a general loss of observations, the model with more than 11 lags started to misbehave.

\section{Data and misspecification tests}

The data in the empirical analysis of the crude oil market and EMU exports are monthly over 2002:01 to 2015:07 (175 observations in levels). Data on technological structure of EMU exports were drawn from Eurostat database and seasonally adjusted afterwards using Census X-13. The world crude oil production in thousands of barrels per day averaged monthly (from the US Energy Information Administration, EIA) are used as a proxy for oil supply. The real price of oil of refiner's acquisition cost of imported crude oil was obtained from Bloomberg. To measure the real economic activity, we use Kilian's index originally shown in Kilian (2009). ${ }^{8}$ The data enter the model in annualized growth rates.

\footnotetext{
${ }^{8}$ The updated index can be found here: http://www-personal.umich.edu/ lkilian/reaupdate.txt
} 
Figure 3 illustrates monthly crude oil production and oil-price development over 2003:01 to 2015:07. From the inspection of these time series we are able to see the timing of the outbreak of major events causing higher oil-price or production volatility. We can see that oil shocks are caused by well-known geopolitical events such as the Iraq War starting in 2003, oil spike in 2008 and Arab Spring in 2011.

\section{Figure 3 Crude oil production and oil-price development}

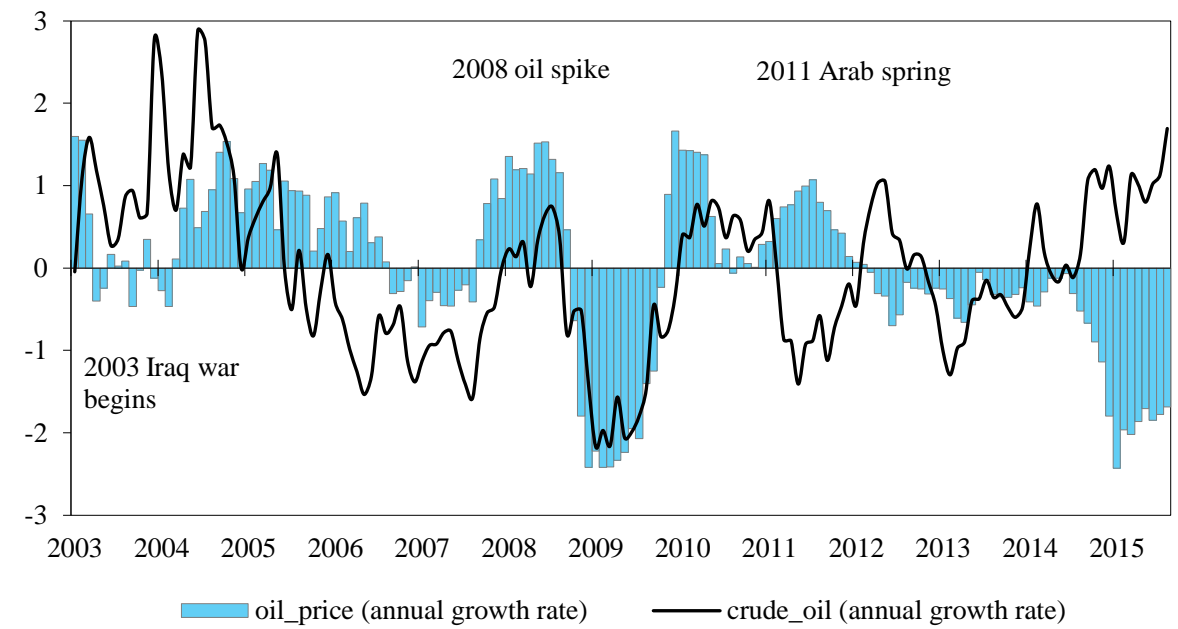

Source: EIA and Bloomberg

Note: for the sake of clarity, variables were z-score normalized.

Before we proceed to the empirical analysis, we need to perform some misspecification tests. First, we test our used variables for stationarity by conducting DF-GLS and NgPerron tests. The variables are tested in their natural logarithm and tests results are reported in the Appendix, Table 1. We cannot reject the null hypothesis that variables in levels contain a unit root at the $1 \%$ significance level. They appear stationary in their first differences. Second, Kang et al. (2015) suggest testing the presence of a cointegration relationship in oil market to confirm the validity of using a VAR framework over VECM for the following analysis. We perform cointegration test based on the methodology presented in Johansen and Juselius (1990) for world oil production and oil-price. Results in Appendix, Table 2 show that a long-run relationship does not exist among the two analysed variables (these results are consistent with findings in Apergis and Miller, 2009).

\section{Empirical results}

In this section, we show evidence on how the parameters of the model have changed over time. Figure 4 plots the posterior means of standard deviations of errors in the VAR equations (posterior means of the square root of the diagonal matrix). This allows us to show the volatility of exogenous shocks in relations to oil market and EMU export 
structure. The standard deviation of residuals in the oil production equation (i.e. the supply side) can be described as volatile during the analysed period with a few spikes. We can detect especially high volatility of exogenous shocks during the financial crisis in 2008-2009 and associated oil spike and extreme volatility build-up taking place since the end-2014 as a result of OPEC's policy of excessive oil production in order to maintain its market share. Also U.S. increasing oil production via shale fracking technology and economic growth slow-down in emerging markets such as China increased oil production volatility. In the export equations, the standard deviations are relatively flat and low in values, suggesting only minor effect of exogenous shocks with the obvious exception being the financial crisis 2008-2009. Exogenous shocks have played some role also in oil-price volatility. Standard deviations are comparatively high during the oil spike in 2009 but they have been declining ever since.

In comparison to oil market development, EMU export is much less volatile during the entire sample period. The analysis of the elasticity of demand for EMU exports has shown that EMU exports are mostly inelastic to price changes. Elasticity occurs only in times of great economic changes, such as the crisis in 2008/2009. Next reason for the low volatility of EMU exports is geographical and product diversification. In geographical terms, the EMU countries export mainly to the rest of the European Union and other developed countries and to the emerging countries which exhibits a high and stable economic growth during the last two decades. To support this claim, we calculated the Herfindahl-Hirschman index of geographical diversification of EMU countries export. We found that geographical diversification of EMU export is very high, reaching the value of 0.24 . Hence very low concentration of export destination indicates low vulnerability of export channel to external economic changes.

Another reason for the low volatility of exports is an ongoing multilateral liberalization and various business tools that insure exporters against unexpected economic events (long-term contracts, insuring the foreign exchange risks such as currency forwards, futures, etc.)

Figure 4 Posterior means of standard deviations of errors in the VAR equations
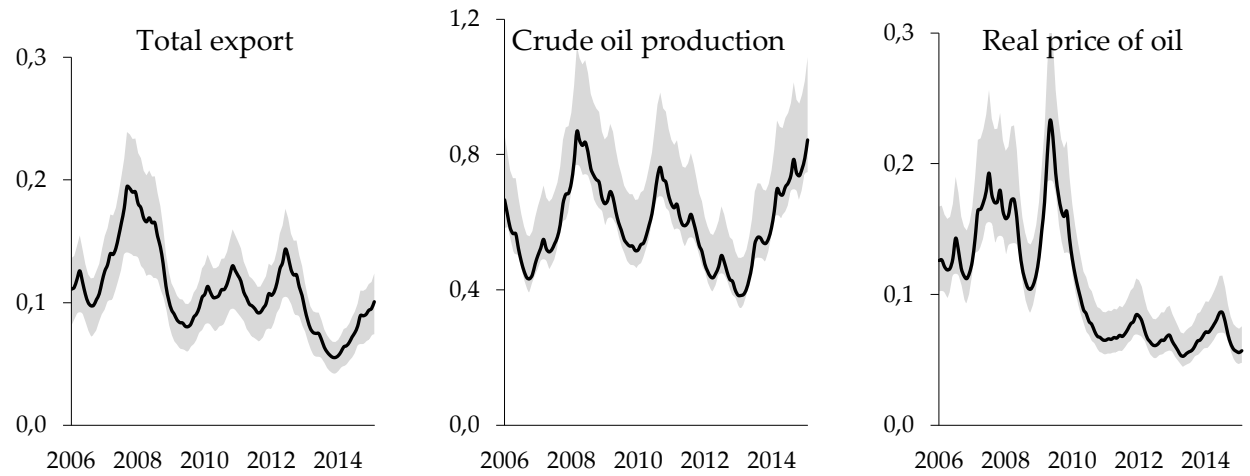

Source: authors

Note: posterior means and 10-th and 90-th percentiles of the standard deviation of residuals of the export equation, the crude oil equation and the oil price equation. 
Next, we utilize the time-varying structural VAR model to investigate the impulse responses of technological structure of EMU export to (a) oil supply shock, (b) aggregate demand shock and (c) oil-specific demand shock. We use a one standard deviation shock, i.e. a shock of the same probability, not of the same size. Note that to simplify an economic interpretation of obtained statistical results, the responses were normalized to account for a 100 basis point shock.

To calculate the impulse responses, we run the MCMC algorithm executed 50,000 times with the first 20,000 burn-in draws (discarded for convergence). For breaking the autocorrelation of the draws, only every $10^{\text {th }}$ iteration is kept. To assess the convergence of MCMC algorithm, we follow Primiceri (2005) and use various autocorrelation measures and Raftery and Lewis (1992) diagnostics. The convergence diagnostics results are satisfactory and the sample autocorrelation functions of the draws die out rather quickly. ${ }^{9}$

The time-variation structure also allows us to estimate these responses in different dates for comparison purposes. First, we analyze the time-varying structure of oil-market responses to different shocks in order to better understand the nature of oil market behavior and second, we turn our attention to discussion of EMU export technological structures response to specified innovations. For a better illustration of the difference in the impulse responses to defined innovations, we first present results for two specific points in time (2007:01 and 2015:01). The two time periods for the comparison are chosen arbitrarily but in a way to capture different oil-market environment. We aim to test whether the relationships between oil market and trade has somewhat changed due to high oil-market volatility in the 2008-09, 2011 and 2014.

\section{Dismantling oil-market responses to oil-related innovations}

This exercise should shed some light on the oil market behavior when hit by an: (a) oil supply shock, (b) aggregate demand shock and (c) oil-specific demand shock. Figure 5 shows the responses of real oil price, crude oil production and real economic activity to one-standard deviation structural innovations described above. It plots the median responses in given times to show whether the response has somewhat changed through time. If so, the responses are also depicted in Figure 6 which provides the estimated medians of the posterior distributions and its evolution through time from 2007 to 2015.

\footnotetext{
${ }^{9}$ We use Econometric Toolbox described in LeSage (1999). The autocorrelation function reports low values, thus showing the draws are independent of each other. The diagnostics concerning the inefficiency factors show very low values. The details are summarized in Table 3 in the Appendix
} 
Figure 5 Impulse responses to different oil market innovations in 2007:01 and 2015:01

(a) Supply shock (increase in crude oil production)
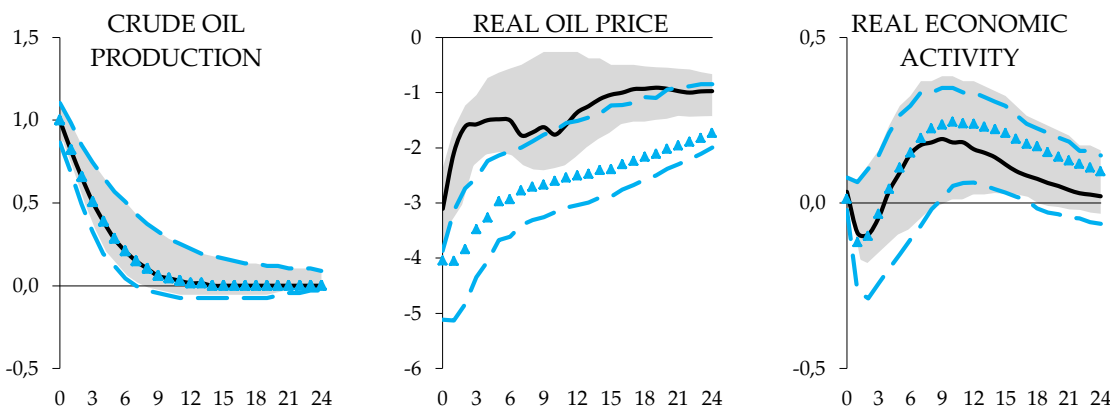

(b) Aggregate demand shock (increase in real global economic activity)
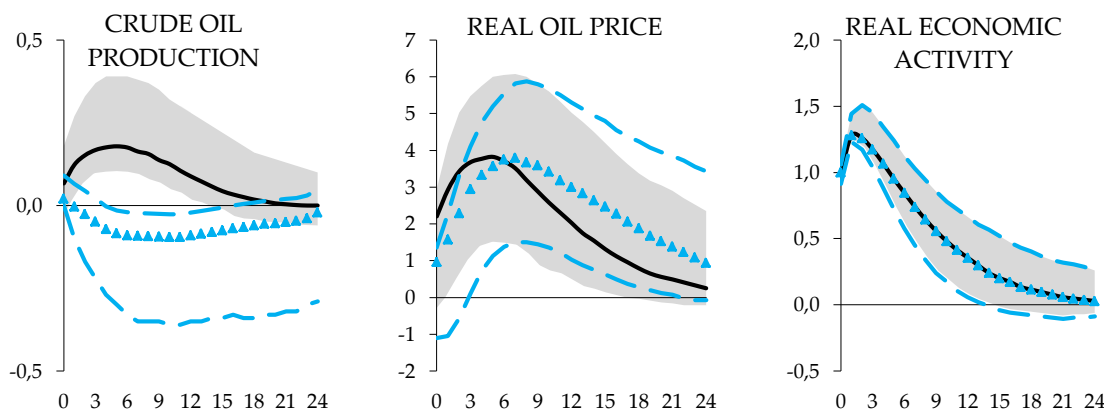

(c) Oil-specific demand shock (increase in real price of oil)
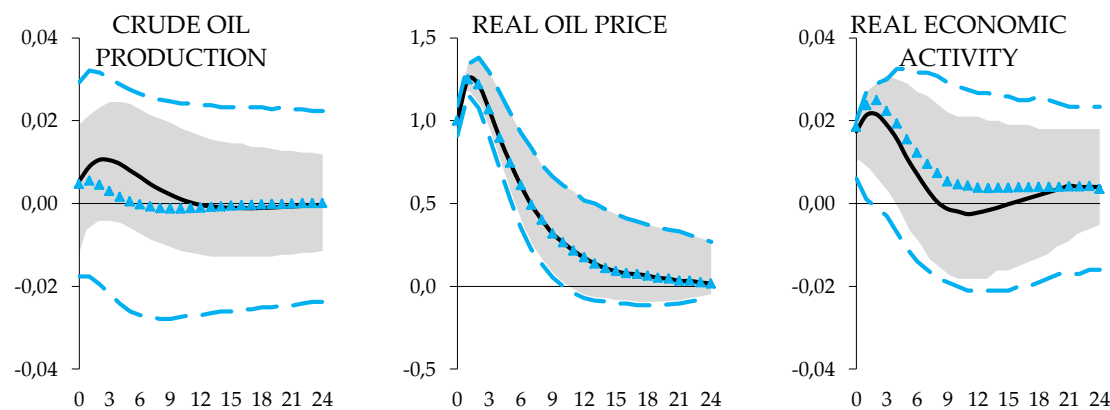

90\% confidence bound (2007:01)

2007:01

$--\cdot 90 \%$ confidence bound (2015:01)

- 2015:01

Source: authors

Note: median impulse responses are reported with $10 \%$ and $90 \%$ probability bands. Responses were normalized to account for the 100 basis point positive innovation. The $y$-axis measures the strength of response variables in percentages; the $x$-axis is in months after the shock. 
First, an unexpected increase in crude oil production (Figure 5a) causes oil prices to decrease upon impact. The response is time-varying as we can detect some differences in responses magnitude through time. The real oil price is more sensitive to oil production changes in 2015 than in 2007 (Figure 6a). This evidence suggests that oil-price is nowadays more sensitive than prior the financial and economic crisis, mainly due to the political situation at the Middle East. In line with economic theory and the notion of lagged VAR models, the real global economic activity increases after 7 to 9 months after the original shock introduction. The economy does not react to increase in crude oil production as such but it increases production due to lower costs as a result of decrease in oil prices (hence the lagged response). The response of real economic activity is mostly time-unvarying what we can see from inspection of responses between 2007 and 2015. Compared to oil-price response, real economic activity reacts similarly during the whole period.

Second, the unanticipated aggregate demand expansion (Figure 5b) significantly influences oil market developments. It increases oil prices while much of the increase in the real price of oil triggered by this shock is delayed by half a year. Figure $6 \mathrm{~b}$ shows the response through the entire sample and it is evident that the oil markets were especially sensitive to changes in global demand during structural events such as the oil spike in 2008 and Arab spring in 2011. More recently, the oil markets again exhibit some volatility due to political situation in the Middle East region. However, oil price reaction to economic activity shock is more delayed due to shortage of oil supply in 2014-2015 caused by low oil-prices.

The most interesting is the reaction of crude oil production as it is heavily time dependent (Figure 6c). While the increase in global demand caused an increase in global oil production (again with a delay of half a year) in 2007 or 2008, the response changed in 2015 with the oil production declining. While we do not have clear explanation, we provide here several explanations why that happened. First, the expectation about the future development in EMU and other developed countries was highly uncertain. Second, the oil prices were at very low levels in 2015 , hence any attempts to increase production would result in additional decline of oil prices. Partially, such expectations among producers were completed by expectation about the technological development in car industry which may eliminate significant part of oil production from the market in the future. 


\section{Figure 6 3D plot of time-varying responses to oil market innovations}

a. Real oil price response to increase in crude oil production

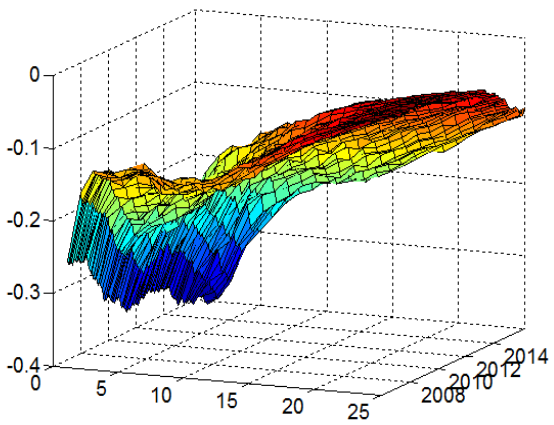

c. Crude oil production response to increase in real global economic activity

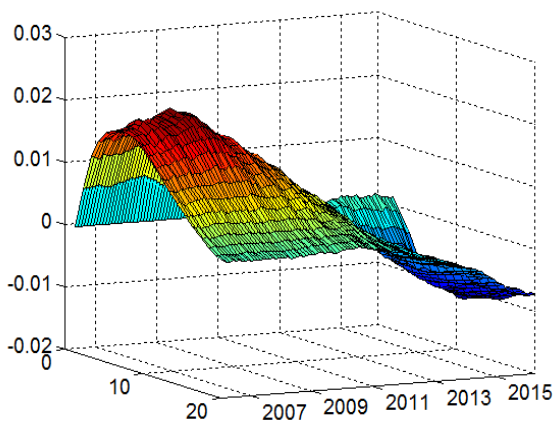

b. Real oil price response to increase in real global economic activity

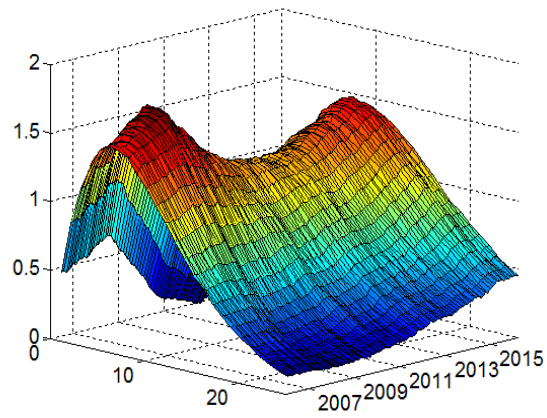

d. Crude oil production response to increase in oil price

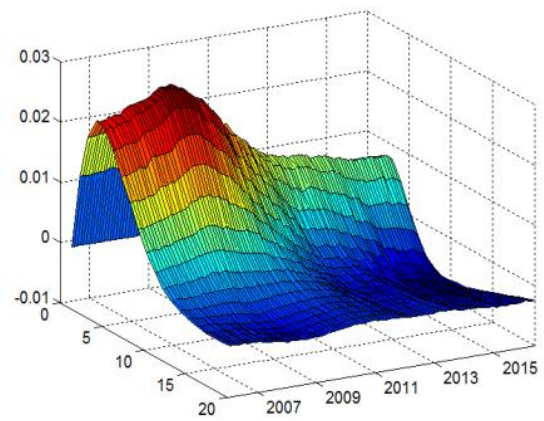

Source: authors

Note: the median impulses were calculated using 50,000 simulations with 20,000 burn-in draws. Vertical axis: strength of the response to a one standard deviation shock. Front axis left: months after the shock. Front axis right: years.

Third, we show the response to unanticipated oil-market specific demand shock increasing the real price of oil (Figure 5c). This shock is associated with a temporary time consistent increase in real economic activity and a very short-run increase in oil production, however, their reaction is marginal at the very best and is not statistically significant. These results, however, correspond with the findings of Riggi and Venditti (2015) as they found the implication of this shock on oil production to be silent as well. Additionally, oil producers are much more sensitive to oil markets innovations during volatility times caused by either political or economic events (Figure 6d). 


\section{Technological structure response to oil market innovations}

We continue our analysis by investigating whether and how the response of EMU exports to unexpected oil-market innovations has changed over time. These changes are summarized in Figures 7 to 8.

In Figure 7, we display the IRFs of export technological structures to oil-market innovations. First, when a positive oil supply shock hits, the EMU exports increase in total (Figure 7a). Since the increase in oil production is likely to reduce oil prices, the rise in export may be explained by lower production and transportation costs. The responses remained unchanged in different time periods both in terms of size and sign.

Second, the IRFs of EMU exports to aggregate demand shocks are much more timevarying (Figure $7 \mathrm{~b}$ and Figure 9 in the Appendix). In this case, all responses are positive, but their magnitude is different across types of exports as well as across time. As mentioned above, the key feature of low-tech products is low income elasticity. Low-tech exports gradually increase in the horizon of one year, however, medium-tech exports increased immediately, peaking in nine months. Increased aggregate demand is transmitted to consumption of goods with higher added value. Increase of high-tech exports is delayed also by nine months. Decrease of high-tech exports in the first months is a result of delayed investment decisions and termination/change of contracts. It is relatively easy to decide about buying clothes or cars than about aircrafts. The responses are higher and statistically significant during the 2007 to 2009 but the sensitivity of EMU exports to changes in demand drops over time. It seems that the EMU exports have become less sensitive to global activity shocks over the past decade. However, we test the pre-crisis, crisis and post-crisis period, therefore the sensitivity of export was higher in the turbulent years between 2007 and 2011.

Third, we provide the response of EMU exports to oil-specific demand shock (Figure $7 \mathrm{c})$. In total, the responses are not significant and are very low. The effect here is not absolutely clear, as it was already stressed in the previous section. Moreover, Riggi and Venditti (2015) came with a similar finding. As we explained in the previous subsection, positive oil-price shock increases economic activity only marginally and thus cannot be reflected in export in a different manner. 
Figure 7 Impulse responses of export technological structure to oil market innovations in 2007:01 and 2015:01

(a) Supply shock (increase in crude oil production)
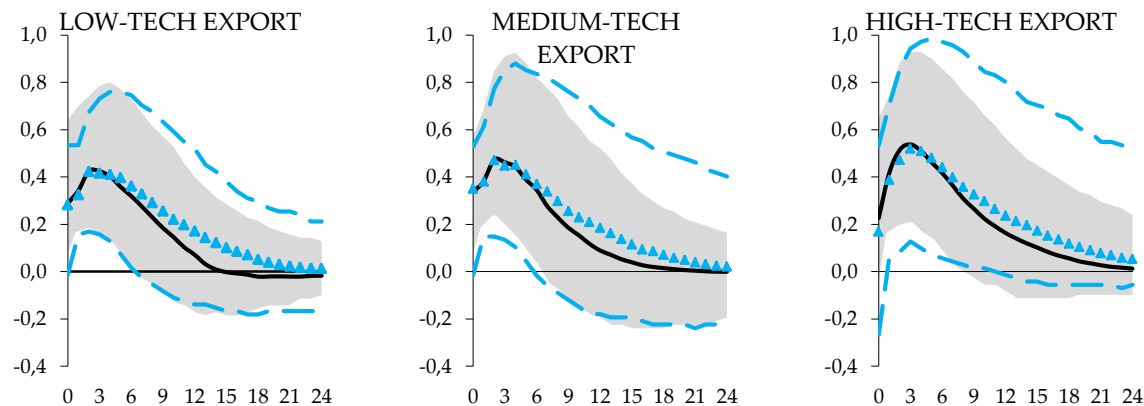

(b) Aggregate demand shock (increase in real global economic activity)
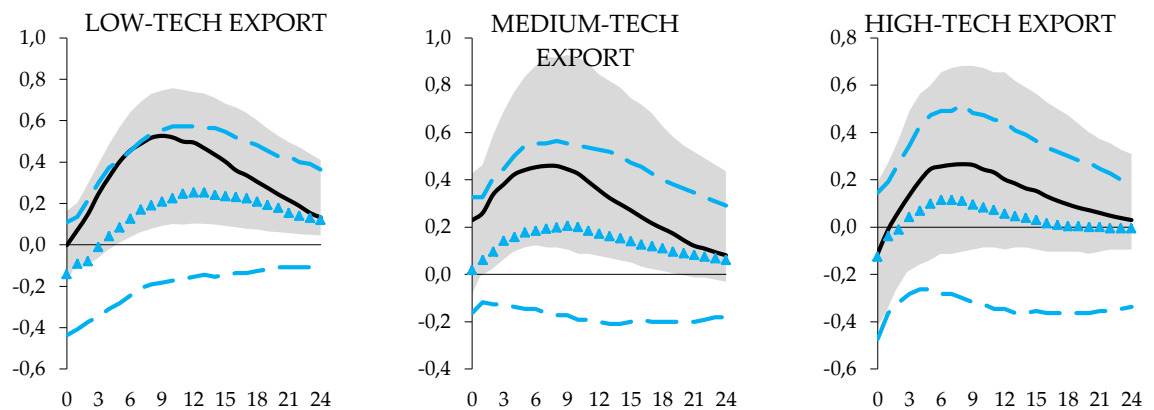

(c) Oil-specific demand shock (increase in real price of oil)
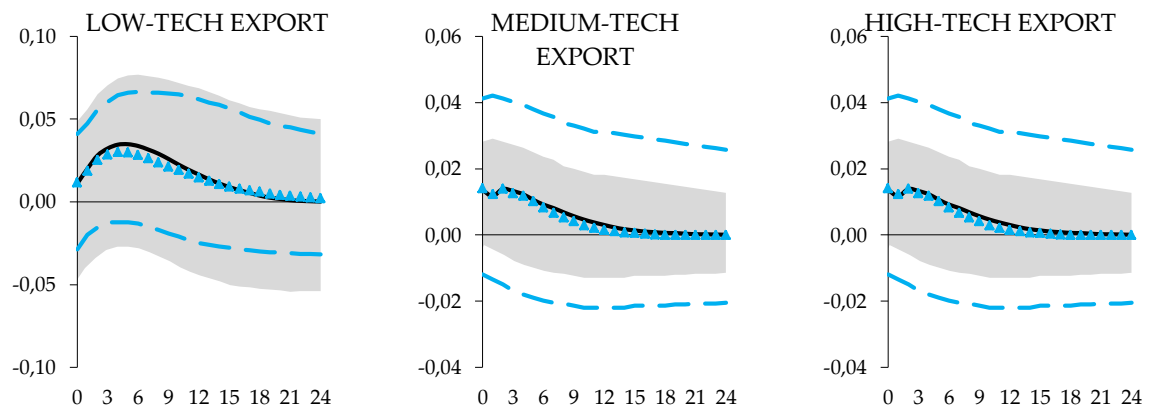

$90 \%$ confidence bound (2007:01)

2007:01

$--.90 \%$ confidence bound $(2015: 01)$

4 2015:01

Source: authors

Note: median impulse responses are reported with $10 \%$ and $90 \%$ probability bands. Responses were normalized to account for the 100 basis point positive innovation. The y-axis measures the strength of variables response in percentages; the $x$-axis is in months after the shock. 


\section{Conclusion}

This paper provides some new empirical evidence on the relationship between oilmarket fluctuations and technology structure of EMU exports. We use a time-varying parameter VAR model and impulse responses to capture the reaction of exports in different stages of their technological level to different oil-market innovations as one of the main drivers of industrial economic performance.

The preliminary analysis of posterior means of standard deviations of errors in our VAR equations points to a few interesting findings. The oil-market development was found to be rather volatile during the entire analyzed period with just a few notable spikes (the financial crisis of 2008-09, Arab spring and OPEC's on-going policy of excessive crude oil production taking place since end-2014). In comparison to oil-market development, EMU exports exhibit much less volatility in time. However, they are also a subject to extreme market events, such as the global economic crisis.

Next, we utilize the time-varying structure of oil-market responses to different shocks to get a better grasp of the market behavior. First, we find that unexpected oil supply shock causes the oil prices to drop at impact. The responses are as follows: time-varying and oil-prices are much more sensitive to oil supply shocks in the post-financial crisis period due to uncertain political situation at the Middle East region. Second, the aggregate demand shock increases oil-prices with a 6-month delay. The oil-prices were especially sensitive to changes in global demand during the rare structural events of 2008 (oil spike) and 2011 (Arab spring). The response of crude oil production to global demand shock is heavily time dependent as it is positive at first (during the first half of our sample from 2007-2013), but negative from 2014. Part of the explanation is that oil supply disruptions in one region tend to trigger expansions of oil production elsewhere. Third, when the market was hit by an oil-specific demand shock (which increases oil-prices), oil production temporarily increases.

Finally, we investigate the effects of oil-market innovations on the technological level of EMU exports. Our results can be summarized in a few stylized facts: (1) increase in crude oil production is likely to reduce oil prices and therefore increases EMU exports due to lower production and transportation costs; (2) increase in global demand is transmitted differently to export technological levels. While the low-tech exports increase gradually in one year after the shock, medium-tech exports increase immediately. This means that the increased aggregate demand is more likely to be transmitted to goods with higher added value. High-tech exports decrease in the first months after the shock as a results of delayed investment decision process; (3) increasing the oil-prices does not affect the EMU exports in a significant manner.

Funding: This work was supported by SGS project [SP2015/106] of Faculty of Economics, VŠB-TU Ostrava and Operational Programme Education for Competitiveness [Project CZ.1.07/2.3.00/20.0296].

Disclosure statement: No potential conflict of interest was reported by the authors. 


\section{References}

ALQUIST, R., and KILIAN, L. (2010). What Do We Learn from the Price of Crude Oil Futures? Journal of Applied Econometrics 25(4): 539-73.

AASTVEIR, K. A., BJORNLAND, H. C., and THORSRUD, L. A. (2015). What Drives Oil-price? Emerging versus Developed Economies. Journal of Applied Econometrics 30(7): 1013-1028. DOI: $10.1002 / \mathrm{jae} .1159$

APARGIS, N., and MILLER, S. M. (2009). Do structural oil-market shocks affect stock price? Energy Economics 31(1): 569-575. DOI: 10.1016/j.eneco.2009.03.001

BACKUS, D., and CRUCINI, M. (2000). Oil-price and the Terms of Trade. Journal of International Economics 50(1): 185-213. DOI: 10.1016/S0022-1996(98)00064-6

BAFFES, J. (2007). Oil Spills on Other Commodities. Resources Policy 32(3): 126-134. DOI: $\underline{10.1016 / \text { j.resourpol.2007.08.004 }}$

BAO, N. K. (2014). Impacts of Oil Shocks on Trade Balance. SSRN Electronic Journal. DOI: $10.2139 /$ ssrn.2381338.

BARSKY, R. B., and KILIAN, L. (2002). Do we really know that oil caused the great stagflation? A monetary alternative. NBER Macroeconomics Annual 2001 16(1): 137198.

BAUMEISTER, Ch., and PEERSMAN, G. (2013). Time-Varying Effects of Oil Supply Shocks on the US Economy. American Economic Journal: Macroeconomics 5(4): 1-28.

BERNANKE, B., GERTLER, M., and WATSON, M. (1997). Systematic monetary policy and the effects of oil-price shocks. Brookings Papers on Economic Activity 1(1): 91-157. DOI: $10.2307 / 2534702$

BLANCHARD, O., and GALÍ, J. (2009). The Macroeconomic Effects of Oil-price Shocks: Why are the 2000s so different from 1970s? In J. GALÍ and M. GETLER, ed., Internationa Dimensions of Monetary Policy, Vol. 1, pp. 373-421. Chicago, University of Chicago Press.

BLANCHARD, O., and RIGGI, M. (2013). Why are the 2000s so different from the 1970s? A structural interpretation of changes in the macroeconomic effects of oil-price in the US. Journal of the European Economic Association 11(5): 1032-1052. DOI: 10.1111/jeea.12029

BROWN, S. P., and YUCEL, M. K. 2002. Energy price and Aggregate Economic Activity: An Interpretative Survey. The Quarterly Review of Economics and Finance 42(1): 193-208.

BUETZER, S., HABIB, M. M., and STRACCA, L. (2012). Global exchange rate configurations: do oil shocks matter? European Central Bank Working Paper No 1442: 132 .

COLOGNI, A., and MANERA, M. (2008). Oil-price, Inflation and Interest Rates in a Structural Cointegrated VAR Model for the G-7 Countries. Energy Economics 30(3): 856-888. DOI: $\underline{10.1016 / j . e n e c 0.2006 .11 .001}$ 
CUNADO, J., JO, S., and PEREZ DE GARCIA, F. (2015). Revisiting the Macroeconomic Impact of Oil Shocks in Asian Economies. Bank of Canada Working Paper 201523: $1-28$.

DOORN, D. J. (2006). Consequences of Hodrick-Prescott Filtering for Parameter Estimation in a Structural Model of Inventory Behavior. Applied Economics 38(16): 1863 1875. DOI: $\underline{10.1080 / 00036840500427254}$

EDELSTEIN, P., and KILIAN, L. (2009). How Sensitive Are Consumer Expenditures to Retail Energy Price? Journal of Monetary Economics 56(1): 766-779. DOI: 10.1016/j.jmoneco.2009.06.001

ELDER, J., and SERLETIS, A. 2010. Oil-price Uncertainty. Journal of Money, Credit and Banking 42(6): 1137-1159. DOI: 10.1111/j.1538-4616.2010.00323.X

GOSSÉ, J. B., GUILLAUMIN, C. (2011). The Impact of External Shocks on the Eurozone: a Structural VAR model. LMCE, King's College London, Working Paper No. 2010-03: 1-26.

HAMILTON, J. (1983). Oil-price and the Macroeconomy since World War II. Journal of Political Economy 91(1): 228-248. DOI: $10.1086 / 261140$

HAMILTON, J. 2008. Oil and the Marcoeconomy. New Palgrave Dictionary of Economics: Palgrave McMillan Ltd..

HAMILTON, J. (2009). Causes and Consequences of the Oil Shock of 2007-08. Brookings Papers on Economic Activity 40(1): 215-261. DOI: 10.1353/eca.0.0047

HAMILTON, J. (2012). Oil prices, exhaustible resources, and economic growth. NBER Working Paper No. w17759.

JO, S. 2014. The Effects of Oil-price Uncertainty on Real Global Economic Activity. Journal of Money, Credit and Banking 46(6): 1113-1135. DOI: 10.1111/jmcb.12135

JOHANSEN, S., and JUSELIUS, K. (1990). Maximum Likelihood Estimation and Inference On Cointegration - With Applications to the Demand For Money, Oxford Bulletin of Economics and Statistics 52(2): 169-210.

KANG, W., RATTI, A. R., and K. H. YOON. Time-varying effect of oil market shocks on the stock market. Journal of Banking \& Finance 61(2): 150-163. DOI: 10.1111/j.1468-0084.1990.mp52002003.x

KILIAN, L. (2008). The Economic Effects of Energy Price Shocks. Journal of Economic Literature 46(4): 871-909. DOI: 10.1257/jel.46.4.871

KILIAN, L. (2009). Not All Oil Price Shocks Are Alike: Disentangling Demand and Supply Shocks in the Crude Oil Market. American Economic Review 99(3): 1053-1069. DOI: $\underline{10.1257 / \text { aer.99.3.1053 }}$

KILIAN, L., and HICKS, B. (2012). Did Unexpectedly Strong Economic Growth Cause the Oil-price Shock of 2003-2008? Journal of Forecasting 32(5): 385-394. DOI: $\underline{10.1002 / \text { for. } 2243}$ 
KILIAN, L., and MURPHY, D. P. (2014). The role of inventories and speculative trading in the global market for crude oil. Journal of Applied Econometrics 29(1): 454-47. DOI: $10.1002 /$ jae. 2322

KILIAN, L., REBUCCI, A., and SPATAFORE, N. (2009). Oil Shocks and External Balances. Journal of International Economics 77(2): 181-194. DOI: 10.1016/j.jinteco.2009.01.001

KILIAN, L. (2010). Oil-price Volatility: Origins and Effects. WTO Staff Working Paper No ERSD-2010-02: 1-35.

KOOP, G., LEON-GONZALES, R., and STRACHAN, R. (2009). On the evolution of the monetary policy transmission mechanism. Journal of Economic Dynamics and Control 33(1): 997-1017. DOI: 10.1016/j.jedc.2008.11.003

KOROBILIS, D. (2013). Assessing the transmission of monetary policy using timevarying parameter dynamic factor models. Oxford Bulletin of Economics and Statistics 75(1): 157-179. DOI: 10.1111/j.1468-0084.2011.00687.x

KORHONEN, I., and LADYAEVA, S. (2010). Trade Linkages and macroeconomic Effects of the Price of Oil. Energy Economics 32(4): 848-856. DOI: 10.1016/j.eneco.2009.11.005

LALL, S. (2000). The technological structure and performance of developing country manufactured exports, 1985-98. Oxford development studies 28(3): 337-369.

LARDIC, S., and MIGNOV, V. (2008). Oil-price and Economic Activity: An Asymmetric Cointegration Approach. Energy Economics 30(3): 847-855. DOI: 10.1016/j.eneco.2006.10.010

LE, T. H., CHANG, Y. (2013). Oil-price Shocks and Trade Imbalances. Energy Economics 36(1): 78-96. DOI: 10.1016/j.eneco.2012.12.002

LEE, K., and NI, S. (2002). On the Dynamic Effects of Oil-price Shocks: A Study Using Industry Level Data. Journal of Monetary Economics 49(1): 823-852. DOI: 10.1016/S0304-3932(02)00114-9

PEERSMAN, G. (2005). What Caused the Early Millennium Slowdown? Evidence Based on Vector Autoregressions. Journal of Applied Econometrics 20(1): 185-207. DOI: $\underline{10.1002 / j a e .832}$

PEERSMAN, G., and VAN ROBAYS, I. (2009). Oil and the Euro Area Economy. Economic Policy 24(1): 603-651.

PRIMICERI, G. E. (2005). Time Varying Structural Vector Autoregressions and Monetary Policy. Review of Economic Studies 72(3): 821-852. DOI: 10.1111/j.1467937X.2005.00353.X

RASMUSSEN, T. N., and ROITMAN, A. (2011). Oil Shocks in the Global Perspectives: Are They Really that Bad? IMF Working Paper No 194: 1-28.

RIGGI, M., and VENDITTI, F. (2015). The Time-Varying Effect of Oil-price Shocks on Euro-Area Exports. Journal of Economic Dynamics and Control 59(1): 75-94. DOI: 10.1016/j.jedc.2015.07.002 
RUBIN, J. (2009). Why Your World is about to Get a Whole Lot Smaller: Oil and the End of Globalization. New York: Random House.

SCHUBERT, S. F. (2009). Dynamic Effects of Oil-price Shocks and Their Impact on the Current Account. Macroeconomic Dynamics 18(2): 316-337. DOI: $\underline{10.1017 / S 1365100512000405}$

\section{Appendix}

\section{A.1 Prior selection process}

To calibrate the prior distribution, we use the first 40 observations as a training sample. Meaning, the mean and the variance of $B_{0}$ are chosen to be the OLS point estimates and four times its variance in a time-invariant VAR, estimated on our small initial training sample. For the log standard errors, the prior mean is specified as the log of the respective OLS point estimates, whereas the prior covariance matrix is restricted to be $I_{n}$. The hyperparameters $Q, S, W$ are the covariance matrices of the innovations. Matrices $Q, S, W$ follow the standard inverse-Wishart prior distribution. Summarizing, the prior take following forms:

$$
\begin{array}{ll}
B_{0} & \sim \mathrm{N}\left(\hat{\mathrm{B}}_{\mathrm{OLS}}, 4 \cdot V\left(\hat{B}_{O L S}\right)\right), \\
A_{0} & \sim \mathrm{N}\left(\hat{\mathrm{A}}_{\mathrm{OLS}}, 4 \cdot V\left(\hat{A}_{O L S}\right)\right), \\
\log \sigma_{0} & \sim \mathrm{N}\left(\log \hat{\sigma}_{\mathrm{OLS}}, I_{n}\right), \\
Q & \sim \mathrm{IW}\left(\mathrm{k}_{\mathrm{Q}}^{2} \cdot 40 \cdot V\left(\hat{B}_{O L S}\right), 40\right) \\
\mathrm{W} & \sim \mathrm{IW}\left(\mathrm{k}_{\mathrm{W}}^{2} \cdot 4 \cdot I_{n}, 4\right) \\
\mathrm{S}_{1} & \sim \mathrm{IW}\left(\mathrm{k}_{\mathrm{S}}^{2} \cdot 2 \cdot V\left(\hat{A}_{1, O L S}\right), 2\right) \\
\mathrm{S}_{2} & \sim \mathrm{IW}\left(\mathrm{k}_{\mathrm{S}}^{2} \cdot 3 \cdot V\left(\hat{A}_{2 O L S}\right), 3\right)
\end{array}
$$

where $S_{1}, S_{2}$ denote the two blocks of $S$, similarly to as $\hat{A}_{1, O L S}$ and $\hat{A}_{2, O L S}$ stands for the two correspondent blocks of $\hat{\mathrm{A}}_{\mathrm{OLS}}$. The degrees of freedom are chosen as in Primiceri (2005). 


\section{A.2 Misspecification tests}

Table 1 Stationarity tests results

\begin{tabular}{|c|c|c|c|c|c|}
\hline \multirow{2}{*}{\multicolumn{2}{|c|}{ Variables }} & \multicolumn{2}{|l|}{ DF-GLS test } & \multicolumn{2}{|c|}{$\mathrm{Ng}$-Perron test } \\
\hline & & \multirow{2}{*}{$\begin{array}{l}\text { Intercept } \\
-2.121\end{array}$} & \multirow{2}{*}{$\begin{array}{l}\begin{array}{l}\text { Trend and } \\
\text { intercept }\end{array} \\
-2.486 \\
\end{array}$} & \multirow{2}{*}{$\begin{array}{l}\text { Intercept } \\
-1.153\end{array}$} & \multirow{2}{*}{$\begin{array}{l}\text { Trend and } \\
\text { intercept } \\
-2.326 \\
\end{array}$} \\
\hline \multirow{6}{*}{$\frac{n}{0}$} & crude oil & & & & \\
\hline & real economic activity & -2.498 & -2.539 & -2.315 & -1.135 \\
\hline & oil price & -2.345 & -2.135 & -2.189 & -1.116 \\
\hline & low-tech export & -2.811 & -2.788 & -2.721 & -2.109 \\
\hline & medium-tech export & -2.214 & -2.190 & -2.190 & -1.804 \\
\hline & high-tech export & -2.092 & -1.845 & -2.194 & -1.605 \\
\hline \multirow{6}{*}{ 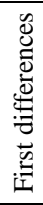 } & crude oil & $-11.135 * * *$ & $-12.981 * * *$ & $-11.156 * * *$ & $-12.531 * * *$ \\
\hline & real economic activity & $-11.315 * * *$ & $-11.156 * * *$ & $-12.156 * * *$ & $-12.486 * * *$ \\
\hline & oil price & $-10.453 * * *$ & $-10.273 * * *$ & $-11.345 * * *$ & $-11.135 * * *$ \\
\hline & low-tech export & $-8.902 * * *$ & $-9.195 * * *$ & $-8.904 * * *$ & $-8.750 * * *$ \\
\hline & medium-tech export & $-8.490 * * *$ & $-8.690 * * *$ & $-8.140 * * *$ & $-8.095 * * *$ \\
\hline & high-tech export & $-7.895 * * *$ & $-8.095 * * *$ & $-7.602 * * *$ & $-7.215 * * *$ \\
\hline
\end{tabular}

Note: The null hypotheses of DF-GLS and Ng-Perron tests: series has a unit root; ***, **, * denote the significance at $1 \%, 5 \%$ and $10 \%$ level respectively.

Table 2 Cointegration test results for the oil market

\begin{tabular}{|l|l|r|r|r|r|}
\hline Rank & $\mathrm{n}-\mathrm{r}$ & Eigenvalue & \multicolumn{1}{|c|}{ Trace Statistic } & 0.05 Critical Value & Prob. $* *$ \\
\hline $\mathrm{r}=0$ & $\mathrm{r}=1$ & 0.045 & 7.341 & 15.494 & 0.538 \\
\hline $\mathrm{r} \leq 0$ & $\mathrm{r}=2$ & 0.000 & 0.005 & 3.841 & 0.942 \\
\hline
\end{tabular}

Note: $r$ denotes number of cointegration vectors, $n-r$ represents number of common trends, **MacKinnon-Haug-Michelis (1999) p-values

Table 3 Distribution of the Inefficiency Factors (of the point 2015:01)

\begin{tabular}{|l|l|l|l|l|}
\hline & Median & Mean & Min & Max \\
\hline A & 1.18942 & 1.58463 & 0.68135 & 3.14893 \\
\hline B & 1.38436 & 1.86453 & 0.35816 & 4.65143 \\
\hline Sigma & 3.86315 & 4.15835 & 1.35131 & 6.31531 \\
\hline
\end{tabular}

Note: Overview of the inefficiency factors (IFs) for the posterior estimates of different sets of time varying parameters. A: time varying simultaneous relations; B: time varying coefficients; sigma: time varying volatilities. 
Figure 8 3D plot of time-varying export structures response to aggregate demand shock

a. Low-tech export

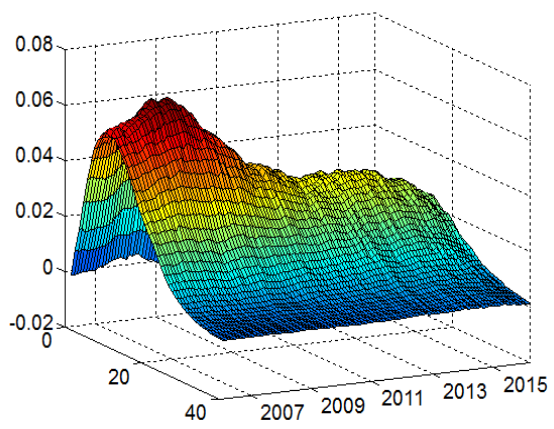

b. Medium-tech export

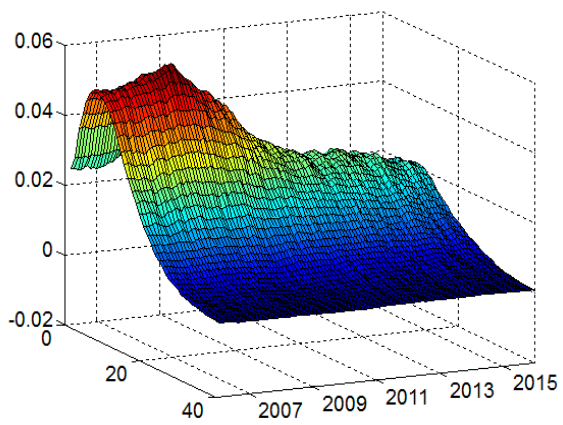

c. High-tech export

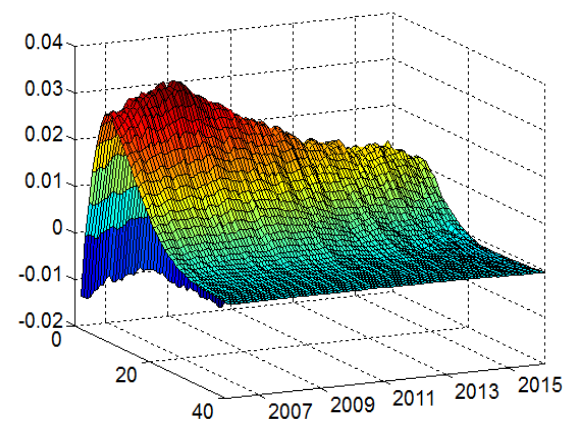

Source: authors

Note: the median impulses were calculated using 50,000 simulations with 20,000 burn-in draws. Vertical axis: strength of the response to a one standard deviation shock. Front axis left: months after the shock. Front axis right: years. 